\title{
PRESERVAÇÃO COGNITIVA: UMA AGENDA PARA O SÉCULO XXI
}

\begin{abstract}
O aumento expressivo e crescente da expectativa de vida que vem ocorrendo nos países desenvolvidos e em desenvolvimento traz aos serviços de saúde um número cada vez maior de indivíduos com queixa de comprometimento cognitivo e com diagnóstico de demência. Dados de um estudo populacional brasileiro recente indicam que quase $40 \%$ das pessoas com 85 anos ou mais têm alguma forma de demência. Entretanto, a despeito desta elevada prevalência, apenas uma pequena parcela destes idosos recebe diagnóstico adequado. Sem dúvida, um dos grandes fatores limi tantes para o reconhecimento das diferentes formas de demência, especialmente em suas fases iniciais, é o conceito errôneo, mas ainda muito difundido, de que o envelhecimento normal se acompanha de declínio cognitivo.

Quando pensamos em uma agenda sobre este tema para o século XXI, o ponto de partida deve ser o aprimoramento da formação dos médicos na área de saúde mental do idoso. Os currículos das faculdades de Medicina devem abrir espaço maior para as disciplinas relacionadas, incluindo aulas sobre transtornos neuropsiquiátricos no idoso, com enfoque em condutas diagnósticas e estratégias de tratamento disponíveis. Em relação aos médicos em atividade, é necessário treiná-los na aplicação de testes e de escalas de avaliação cognitiva e funcional, ferramentas obrigatórias para o diagnóstico das demências. Há inúmeros instrumentos de uso simples e rápido que podem ser empregados com esta finalidade, mas que entretanto são pouco utilizados. Importante salientar ainda que todos os médicos que atendem clientela idosa (e aí estão incluídas quase todas as especialidades médicas) podem se capacitar para o primeiro atendimento destes pacientes.

Infelizmente não dispomos, até o momento, de medidas muito eficazes para o tratamento da doença de Alzheimer ou da demência vascular, as duas principais causas de demência em nosso país. As evidências atuais indicam que as medidas preventivas terão certamente
\end{abstract}

maior impacto que o tratamento destas doenças já instaladas. Sabe-se, por exemplo, que o processo patológico característico da doença de Alzheimer se inicia muitos anos antes dos primeiros sintomas aparecerem, quando já há uma perda sináptica e neuronal significativa e irreversível.

Estudos epidemiológicos de base populacional e de caráter prospectivo têm trazido nos últimos anos contribuições sobre possíveis estratégias de prevenção de tais doenças. Como exemplo, há evidências de associação da exposição a agentes antiinflamatórios não-hormonais com diminuição do risco para desenvolvimento da doença de Alzheimer. Entretanto, essa associação ainda carece de estudos mais aprofundados, particularmente quanto à sua relação temporal e a análises de relação risco-benefício, o que torna precoce, ainda, a utilização desta classe de medicamentos na prevenção da doença.

O papel da terapia de reposição hormonal em mulheres, tido inicialmente como potencial medida de prevenção, foi seriamente abalado após a publicação, em 2003 e agora em 2004, de resultados doWomen's Health Initative Study, indicando aumento da incidência da doença de Alzheimer e de comprometimento cognitivo leve em mulheres que receberam reposição com estrogênio combinado ou não à progesterona. Por outro lado, o controle de diversos fatores de risco de grande relevância na prevenção de doença cere brovascular vem se mostrando também de importância na doença de Alzheimer. Tais evidências são, mais uma vez, oriundas de estudos epidemiológicos, apontando associação direta com índices de aterosclerose, com hipotensão arterial diastólica e hipertensão arterial sistólica e com níveis elevados de homocisteína plasmática, e uma associação inversa com o emprego de estatinas.

Outro capítulo de grande interesse diz respeito ao papel de fatores nutricionais e de substâncias antioxidantes e seu possível papel na prevenção de demência. Em estudo recente, em que 4740 idosos foram acompanhados durante três anos, foi observado que o uso combinado de vitamina $C$ (doses $=500 \mathrm{mg} /$ dia) e de vitamina $E$ (doses $>400 \mathrm{UI} /$ dia) estiveram associados à incidência significativamente menor de doença de Alzheimer. Dados como este abrem perspectivas de novas estratégias de prevenção, embora se saiba que o uso prolongado de doses elevadas destas vitaminas possa também ter efeitos adversos, o que obriga a definição de relações de risco-benefício.

Finalmente, é importante ressaltar os benefícios de medidas não-farmacológicas na prevenção destas doenças. Estudos indicam, por exemplo, que uma maior rede de relacionamento social tem efeito protetor contra o desenvolvimento de demência ou, ainda, que indivíduos casados ou vivendo em co-habitação apresentam menor risco de desenvolver demência em geral e doença de Alzheimer, em particular. Houve, ainda, a observação de que a prática de determinadas atividades de lazer (leitura, jogos, atividade física, tocar um instrumento musical e dança) reduziu a incidência de demência ao final de cinco anos de seguimento.

A constatação do efeito benéfico de atividades estimulantes do ponto de vista cognitivo e afetivo desperta a atenção para a realidade brasileira, que, além das limitações socioeconômicas e educacionais, carece ainda de uma política sólida de atenção à saúde mental e de assistência social dos idosos. É fundamental que se estabeleçam planos de atenção integral a estes indivíduos, que em número cada vez maior serão atendidos nos postos de saúde, ambulatórios e consultórios médicos, estimulando as medidas preventivas observadas, controlando os fatores de risco para demência já conhecidos, realizando diagnóstico mais precoce de condições já estabelecidas e direcionando para as melhores estratégias terapêuticas disponíveis. 